\title{
Correlation with spontaneous pneumothorax and weather change, especially warm front approaching
}

\author{
Yuka Kaneko ${ }^{1}$, Yoshihiro Utsushikawa ${ }^{2}$, Hiroyuki Deguchi ${ }^{1}$, Makoto Tomoyasu ${ }^{1}$, Satoshi Kudo ${ }^{1}$, \\ Wataru Shigeeda ${ }^{1}$, Ryuichi Yoshimura ${ }^{1}$, Hironaga Kanno ${ }^{1}$, Hajime Saito ${ }^{1}$ \\ ${ }^{1}$ Department of Thoracic Surgery, Iwate Medical University, Iwate, Japan; ${ }^{2}$ Iwate Medical University School of Medicine, Iwate, Japan \\ Contributions: (I) Conception and design: Y Kaneko, Y Utsushikawa, H Saito; (II) Administrative support: Y Kaneko, Y Utsushikawa, H Saito; (III) \\ Provision of study materials or patients: Y Kaneko, Y Utsushikawa; (IV) Collection and assembly of data: Y Kaneko, Y Utsushikawa; (V) Data analysis \\ and interpretation: Y Kaneko, Y Utsushikawa, H Saito; (VI) Manuscript writing: All authors; (VII) Final approval of manuscript: All authors. \\ Correspondence to: Yuka Kaneko, MD, PhD. Department of Thoracic Surgery, Iwate Medical University, 2-1-1 Idai-dori, Yahaba, Shiwa, Iwate 028- \\ 3695, Japan. Email: ukaneko@iwate-med.ac.jp.
}

Background: Primary spontaneous pneumothorax (PSP) occurs more frequently in young, tall men, with
approximately 10,000 times video-assisted thoracoscopic surgery (VATS) annually in Japan is undergoing
for surgical treatment. The underlying mechanisms remain unclear, but several reports have suggested
correlation with weather conditions. This study aimed to evaluate the relationship between onset of PSP and
changes in weather. Methods: We retrospectively analyzed data from 112 patients who underwent VATS for PSP in Iwate, Japan from 1 January 2010 to 14 June 2020. Of the 3,818 days in this study period, the day on which the patient became aware of symptoms was classified as the PSP onset day $(n=112)$, and all others were classified as PSP non-onset day $(n=3,706)$. Meteorological data were collected from airbase station using an online source for the same place and same time. Logistic regression modeling was used to obtain predicted risks for the onset of PSP with respect to weather conditions.

Results: Among the meteorological parameters, significant differences were mainly found at 2 days before onset for increasing average temperature [odds ratio (OR): 1.97, $\mathrm{P}=0.018$ ], minimum temperature (OR: 1.97, $\mathrm{P}=0.018$ ), average humidity (OR: $1.58, \mathrm{P}=0.043$ ), and decreased the sunshine time (OR: 2.26, $\mathrm{P}=0.012$ ). No significant difference was observed in atrophic pressure at 2 days before onset.

Conclusions: Onset of PSP may correlate with the increased temperature and humidity, seen with an approaching of warm front.

Keywords: Pneumothorax; atmospheric pressure; temperature; warm front

Submitted Nov 27, 2020. Accepted for publication Jan 20, 2021.

doi: $10.21037 /$ jtd-20-3395

View this article at: http://dx.doi.org/10.21037/jtd-20-3395

\section{Introduction}

Spontaneous pneumothorax (SP) consists of primary spontaneous pneumothorax (PSP) and secondary spontaneous pneumothorax (SSP) (1). PSP is defined as the accumulation of air in the pleural cavity without trauma and nor clinically apparent underlying lung disease (2). The incidence of PSP is estimated to be 6.3 to 18 cases and 1.2 to 6 cases per 100,000 cases annually for men and women, respectively, and it occurs frequently in young, tall men with low body mass index (BMI) $(3,4)$. Video-assisted thoracoscopic surgery (VATS) is performed as surgical treatment for approximately 10,000 cases of PSP annually in Japan (5). In general, the cause of PSP onset is the collapse of bullae, but the triggering mechanism is still unknown in despite advances in treatment (6).

Previous studies have suggested that triggers for the onset of PSP may involve weather conditions such as 


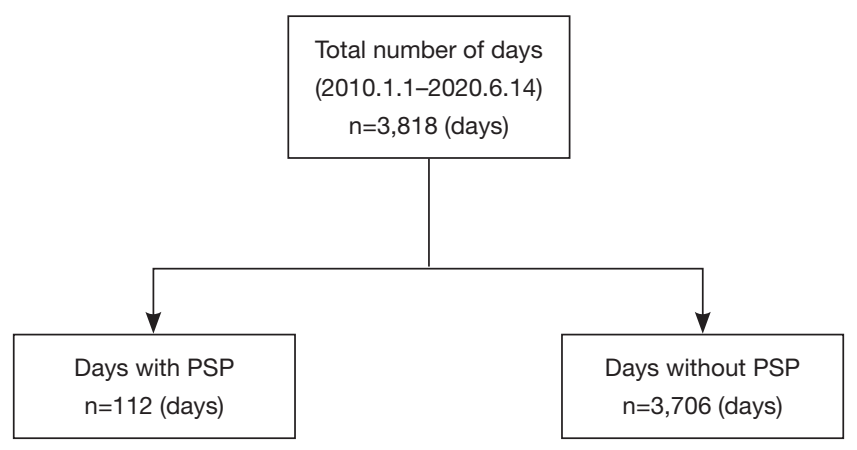

Figure 1 Classification of total days in this study period.

atmospheric pressure (7-10), temperature (11), and duration of sunshine (12), and overexpansion of bullae due to trapped air may trigger the occurrence of PSP after falls in external ambient pressure (7-18). However, some reports have demonstrated no correlation between PSP on set and weather conditions $(15,19-21)$, since no consensus has been obtained to date.

There has been no study conducted on this topic in our region. The aim of this retrospective study was to evaluate the relationship between onset of PSP and weather changes in Iwate, Japan. We present the following article in accordance with the STROBE reporting checklist (available at http://dx.doi.org/10.21037/jtd-20-3395).

\section{Methods}

\section{Patient selection}

Data for this retrospective cohort study were obtained from the medical records of all patients who underwent VATS for PSP between 1 January 2010 and 14 June 2020 (total study period, 3,818 days) at Iwate Medical University Department of Thoracic Surgery. The study was conducted in accordance with the Declaration of Helsinki (as revised in 2013). The study was approved by the institutional review board at Iwate Medical University (permit number: MH2020-115) and individual consent for this retrospective analysis was waived. Of the 450 cases diagnosed with SP from lung collapse confirmed on chest X-ray and computed tomography (CT) imaging, 329 cases with unclear date of onset, iatrogenic pneumothorax, traumatic pneumothorax, chest tube drainage only, differentiation of menstrual pneumothorax, cases without bullae and SSP were excluded SSP was defined as secondary to underlying diseases such as chronic obstructive pulmonary disease (COPD) or interstitial pneumonia (IP). Cases in which the location of occurring pneumothorax was geographically distant from the meteorological station which meteorological data were presumed to be different were also exclude. Recurrence cases was double counted, so finally, 112 cases (106 patients, but 6 had a recurrence once each) met the selection criteria. The onset time of PSP was defined as the time when the symptoms, which were regarded as those induced by the pneumothorax (such as chest pain, back pain, and dyspnea), were clearly exhibited. The visiting time to hospital was initial diagnosis of PSP by chest X-ray and CT. VATS was performed in all cases via three ports with monitor vision only under general anesthesia with a double-lumen endotracheal tube for single lung ventilation.

\section{Meteorological data}

Of the 3,818 days in this study period, the day which the patients became aware of the symptoms was classified as the PSP onset day ( $\mathrm{n}=112$, days with PSP group), and all other days were classified as the PSP non-onset day ( $\mathrm{n}=3,706$, days without PSP group) (Figure 1). Meteorological data were collected from an airbase station using an online source for the same place and same time (22). Daily measurement of meteorological parameters included average atmospheric pressure (hectopascal: $\mathrm{hPa}$ ), average minimum and maximum temperatures $\left({ }^{\circ} \mathrm{C}\right)$, average humidity $(\%)$, average wind speed $(\mathrm{km} / \mathrm{h})$, and total duration of sunshine per day (hour). Changes in each value between the study day and 24, 48, 72, and $96 \mathrm{~h}$ before were assessed for days with and without PSP.

\section{Statistical analysis}

JMP version 14.0.0 statistical software (SAS Institute, Cary, NC, USA) was used for all statistical analyses. Groups were 
Table 1 Patients characteristics

\begin{tabular}{|c|c|}
\hline Characteristics & Value $(n=112)$ \\
\hline \multicolumn{2}{|l|}{ Gender } \\
\hline Male & 100 \\
\hline Female & 12 \\
\hline Age & $23.7 \pm 0.1$ \\
\hline Height (cm) & $172.2 \pm 6.1$ \\
\hline Weight (kg) & $57.1 \pm 7.7$ \\
\hline BMI $\left(\mathrm{kg} / \mathrm{m}^{2}\right)$ & $19.0 \pm 2.2$ \\
\hline \multicolumn{2}{|l|}{ Smoking history } \\
\hline Never & 75 \\
\hline Current & 20 \\
\hline Ex & 17 \\
\hline \multicolumn{2}{|l|}{ Site } \\
\hline Right & 44 \\
\hline Left & 66 \\
\hline Both & 2 \\
\hline \multicolumn{2}{|l|}{ Pneumothorax } \\
\hline Incipient & 70 \\
\hline Recurrence & 42 \\
\hline
\end{tabular}

Value are mean \pm SD.

compared using Pearson's chi-square test or Wilcoxon's rank sum test. Multivariate predictors were evaluated using logistic regression analysis, and odds ratios (ORs) and 95\% confidence intervals (CIs) were estimated. On logistic regression analysis, the conventional receiver-operating characteristic (ROC) curve was used to determine the cutoff for each variable that yielded maximal sensitivity and specificity with respect to predicting occurring PSP in this study population. Differences between groups were considered significant for values of $\mathrm{P}<0.05$. Continuous data are expressed as mean \pm standard deviation, and categorical data are expressed as counts and proportions.

\section{Results}

All 112 cases who underwent VATS for PSP were retrospectively reviewed (Figure 1). Clinical characteristics of the study population are summarized in Table 1. Eligible patients comprised 100 males and 12 females, with an average age of $23.7 \pm 0.1$ years, and BMI was
$19 \mathrm{~kg} / \mathrm{m}^{2}$, so lean men had more PSP occurred. Each type of meteorological data up to 4 days was compared between the days with PSP group ( $\mathrm{n}=112)$ and the days without PSP group $(\mathrm{n}=3,706)$ using univariate analysis, revealing no significant difference between groups (Table 2).

Logistic regression modeling was used to evaluate predicted risks for onset of PSP with respect to weather conditions, revealing a significant difference 2 days before onset for an increase in average temperature (OR: 1.97, $\mathrm{P}=0.018)$, minimum temperature $(\mathrm{OR}: 1.97, \mathrm{P}=0.018)$, average humidity (OR: $1.58, \mathrm{P}=0.043)$, and decreased sunshine time (OR: 2.26, $\mathrm{P}=0.012$ ) (Table 3). No significant difference was observed in atmospheric pressure at 2 days before onset.

The Figure 2 showed the monthly number of PSP. Although there was no significant difference, the prevalence was low in midsummer (August) and midwinter (December), and it seemed that PSP occurred tend to be high at the transition from spring to summer (May and July).

\section{Discussion}

This study evaluated the relationship between onset of PSP and meteorological conditions in 112 eligible cases who underwent VATS in Iwate, Japan. Logistic regression analysis demonstrated that significant difference at 2 days before PSP onset for increasing average temperature (OR: 1.97, $\mathrm{P}=0.018$ ), minimum temperature (OR: $1.97, \mathrm{P}=0.018$ ), average humidity (OR: $1.58, \mathrm{P}=0.043)$, and decreased sunshine time (OR: 2.26, $\mathrm{P}=0.012$ ) (Table 3). No significant difference was observed in atrophic pressure at 2 days before onset. The results from this study indicated that onset of PSP may be related to the increased temperature and humidity likely, the accompanying approach of a warm front.

In Japan, weather changes between the four seasons are clear, because air masses (huge high atmospheric pressure) with greatly different temperatures and humidity change their power depending on the season. Different air masses cover the Japanese archipelago in summer and winter, then stable weather conditions continue. While the weather changes periodically in spring and autumn, because mobile high atmospheric pressure and extratropical cyclones are swept by westerlies (23). This study suggested that the onset of PSP correlated with weather change 2 days earlier. In meteorology, conditions in which an increase in temperature, and humidity, and a decrease in hours of sunshine occur at the same time would match the approach 
Table 2 Comparison of weather conditions on days with and without pneumothorax

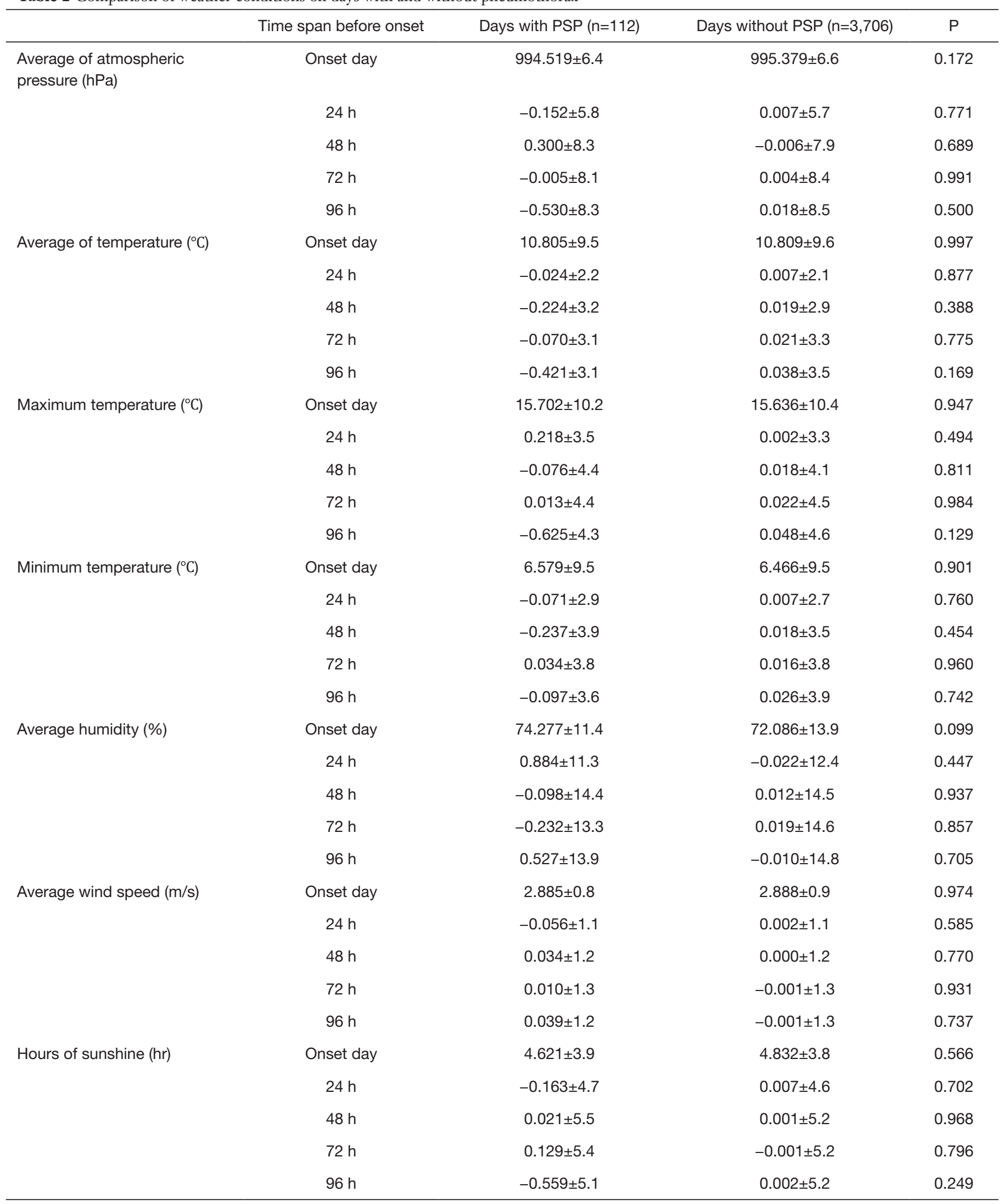

Value are mean $\pm \mathrm{SD}$. 
Table 3 Logistic regression analysis of predictor for onset of PSP

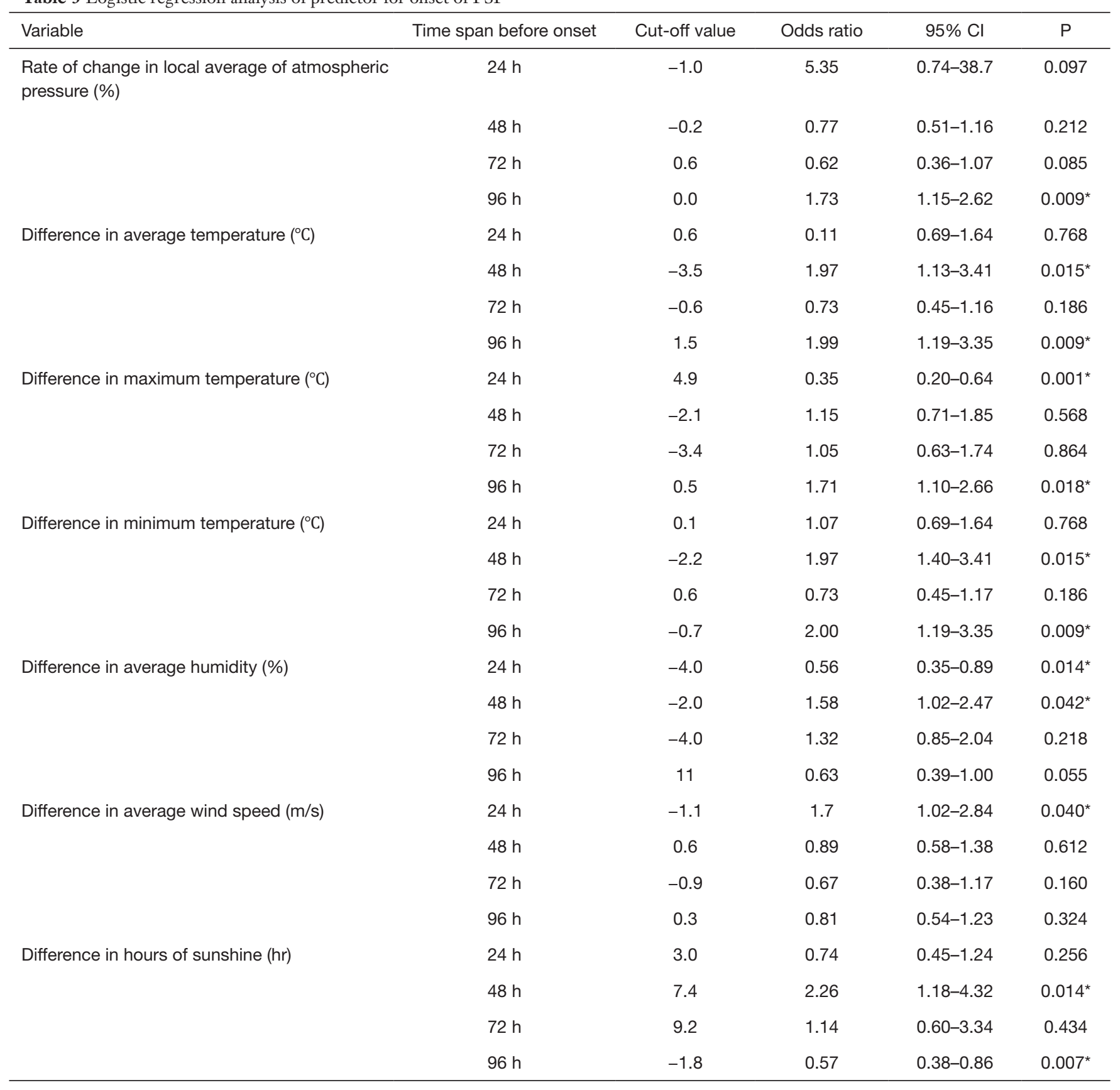

${ }^{*} \mathrm{P}<0.05$.

of a warm front. With a warm front, the temperature rises because the warm air rides on the cold air, and on the front surface, the temperature difference and abundant water vapor carried by the warm air cause a wide range of layered clouds to develop, resulting in relatively long rain fall. This is turn results in increased humidity and decreased hours of sunshine. A previous report from Japan suggested that the rise in temperature and decreased hours of sunshine 2 days earlier correlate with the onset of PSP (18), which is consistent with our result, since the approach of a warm front may cause PSP in Japan. Changes in atmospheric pressure are widely hypothesized to induce PSP, and warm fronts generate an updraft, that decreases atmospheric pressure as the front approach, meeting the conditions for 


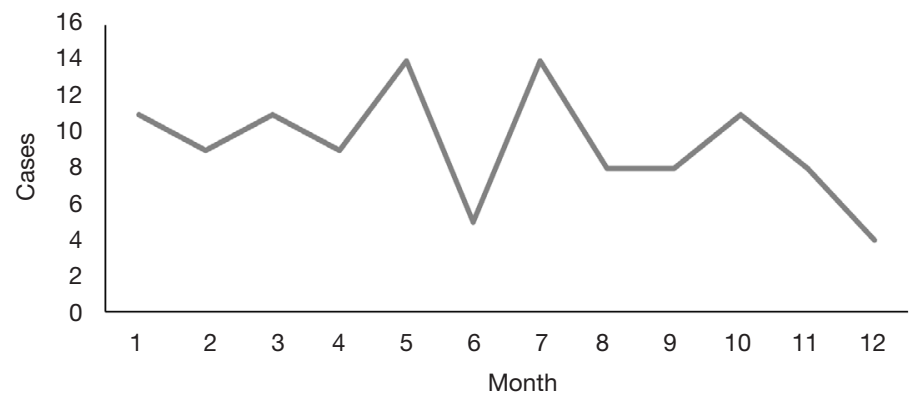

Figure 2 The monthly number of PSP occurring.

PSP onset.

Previous studies have reported that changes in atmospheric pressure are directly or indirectly related to PSP occurrence (7-10). Some reports have found that atmospheric pressure is unrelated to the onset of PSP, and the correlation between PSP onset and weather change thus remains controversial $(15,19-21)$. Regarding the relationship between PSP onset and weather, in addition to changes in atmospheric pressure, temperature (11), hours of sunshine (12), wind speed (13), season (14), tracheal spasm (15), ozone (16) and air pollution concentration (24) have been reported as potential influences. Considering that many studies have reported different results, it is quite possible that PSP does not involve the single factor of atmospheric pressure alone, but multiple factors interacting for a complex effect. In this study, significant increase were observed in temperature and humidity 2 days before PSP onset, but no direct relationship between atmospheric pressure and PSP occurrence could be confirmed. The cause of PSP is the collapse of bullae due to the expansion of the isolated air in the bullae, and pressure and heat are important factors in air volume change (Boyle-Charles' law). These factors correspond to (I) atmospheric pressure and (II) temperature in meteorology. The mechanisms of temperature change include: (I) heat conduction; (II) heat of vaporization; and (III) radiant heat. When the humidity is high, the efficiency of heat conduction and heat of vaporization generally decreases, and the body temperature rises in human body. Since, under hot and humid weather conditions, heat may be less likely to escape from the trachea, rises in core body temperature will cause the air component to tend to expand. Bense et al. reported that a decrease in atmospheric pressure decreasing of $10 \mathrm{hPa}$ or more within 24 hours has a significant effect on the occurrence of PSP (10). This means that the air component expands by $0.99 \%$ when changing from $1 \mathrm{~atm}$
$(1,013 \mathrm{hPa})$, in accordance with Boyle-Charles's law. Based on similar calculations, when the body temperature rises by $1{ }^{\circ} \mathrm{C}$ from 36.5 to $37.5{ }^{\circ} \mathrm{C}$, the air component expands by $0.32 \%$. Therefore, under hot and humid weather conditions, the volume of the air component in the human body is already tending to increasing. If an atmospheric pressure change of about several $\mathrm{hPa}$ is added, air components such as bullae would reach the risk of bursting. Although no significant difference was observed in the change of atmospheric pressure in this study, factors such as temperature, humidity and atmospheric pressure may have deeply interacted, resulting in an effect on the risk of PSP onset. From these research results, a relationship between PSP onset and approach of a warm front is suggested. Of course, when a warm front approaches, atmospheric pressure should decrease secondarily. The atmospheric pressure data used in this study represent daily averages, and no suitable changes were might be observed. The causal relationship with atmospheric pressure should be further verified.

Since the fronts tend to form at the boundary between warm and cold air, so fronts are unlikely to occur in midsummer and midwinter when air masses cover the Japanese archipelago, and they often occur at the turn of the season. In this study, the prevalence of PSP was low in midsummer (August) and midwinter (December), and it seemed that PSP occurred tend to be high at the transition from spring to summer (May and July) (Figure 2). It is presumed that the extremely low occurrence of PSP in June might be related to the fact that the rainy season in Iwate is started in June. In brief, because the rainy front which is a stationary front has occurred, it is considered that there is little change of temperature and humidity rise which are hypothesize to be the cause of PSP.

This study is the first report to assess the approach of a warm front as potentially related to PSP onset in 
Japan. Warm front is fairly familiar information, and as such can be confirmed from daily weather forecasts, representing an index that is generally easy to understand as a pneumothorax warning in our residence area. Although a relationship with PSP onset and atmospheric pressure could not be demonstrated in this study, it is necessary to conduct studies at different areas and further verify the mechanisms.

\section{Acknowledgments}

The authors wish to thank Tatsuo Tanita for his variable suggestion.

Funding: None.

\section{Footnote}

Reporting Checklist: The authors have completed the STROBE reporting checklist. Available at http://dx.doi. org/10.21037/jtd-20-3395

Peer Review File: Available at http://dx.doi.org/10.21037/jtd20-3395

Data Sharing Statement: Available at http://dx.doi. org/10.21037/jtd-20-3395

Conflicts of Interest: All authors have completed the ICMJE uniform disclosure form (available at http://dx.doi. org/10.21037/jtd-20-3395). The authors have no conflicts of interest to declare.

Ethical Statement: The authors are accountable for all aspects of the work in ensuring that questions related to the accuracy or integrity of any part of the work are appropriately investigated and resolved. The study was conducted in accordance with the Declaration of Helsinki (as revised in 2013). The study was approved by the institutional review board at Iwate Medical University (permit number: MH2020-115) and individual consent for this retrospective analysis was waived.

Open Access Statement: This is an Open Access article distributed in accordance with the Creative Commons Attribution-NonCommercial-NoDerivs 4.0 International License (CC BY-NC-ND 4.0), which permits the noncommercial replication and distribution of the article with the strict proviso that no changes or edits are made and the original work is properly cited (including links to both the formal publication through the relevant DOI and the license). See: https://creativecommons.org/licenses/by-nc-nd/4.0/.

\section{References}

1. MacDuff A, Arnold A, Harvey J; BTS Pleural Disease Guideline Group. Management of spontaneous pneumothorax: British Thoracic Society Pleural Disease Guideline 2010. Thorax 2010;65 Suppl 2:ii18-31.

2. Noppen M. Spontaneous pneumothorax: epidemiology, pathophysiology and cause. Eur Respir Rev 2010;19:217-9.

3. Sahn SA, Heffner JE. Spontaneous pneumothorax. N Engl J Med 2000;342:868-74.

4. Ozpolat B, Gözübüyük A, Koçer B, et al. Meteorological conditions related to the onset of spontaneous pneumothorax. Tohoku J Exp Med 2009;217:329-34.

5. Shimizu H, Okada M, Tangoku A, et al. Thoracic and cardiovascular surgeries in japan during 2017: Annual report by the Japanese Association for Thoracic Surgery. Gen Thorac Cardiovasc Surg 2020;68:414-49.

6. Kurihara M, Kataoka H, Ishikawa A, et al. Latest treatments for spontaneous pneumothorax. Gen Thorac Cardiovasc Surg 2010;58:113-9.

7. Mishina T, Watanabe A, Miyajima M, et al. Relationship between onset of spontaneous pneumothorax and weather conditions. Eur J Cardiothorac Surg 2017;52:529-33.

8. AljehaniY, Niaz R, Almajid F, et al. Influence of meteorological factors on the onset of primary spontaneous pneumothorax. Ann R Coll Surg Engl 2018;100:1-6.

9. Akyll M, Tezel Ç, Evman S, et al. Correlation between meteorological changes and primary spontaneous pneumothorax: Myth or fact? Turk Gogus Kalp Damar Cerrahisi Derg 2018;26:436-40.

10. Bense L. Spontaneous pneumothorax related to falls in atmospheric pressure. Eur J Respir Dis 1984;65:544-6.

11. Smit HJ, Devillé WL, Schramel FM, et al. Atmospheric pressure changes and outdoor temperature changes in relation to spontaneous pneumothorax. Chest 1999;116:676-81.

12. Motono N, Maeda S, Honda R, et al. Atmospheric temperature and pressure influence the onset of spontaneous pneumothorax. Clin Respir J 2018;12:557-62.

13. Schieman C, Graham A, Gelfand G, et al. Weather and chinook winds in relation to spontaneous pneumothoraces. Can J Surg 2009;52:E151-5.

14. Accard JL, Patte F, Combes F, et al. Spontaneous pneumothorax. Clinical study, meteorological correlations, course and treatment. Rev Tuberc Pneumol (Paris) 
1972;36:431-46.

15. Bertolaccini L, Cassardo C, Viti A, et al. The relationship between meteorological variations and the onset of spontaneous pneumothorax. Surg Today 2013;43:345-6.

16. Bertolaccini L, Alemanno L, Rocco G, et al. Air pollution, weather variations and primary spontaneous pneumothorax. J Thorac Dis 2010;2:9-15.

17. Bulajich B, Subotich D, Mandarich D, et al. Influence of atmospheric pressure, outdoor temperature, and weather phases on the onset of spontaneous pneumothorax. Ann Epidemiol 2005;15:185-90.

18. Obuchi T, Miyoshi T, Miyahara S, et al. Does pneumothorax occurrence correlate with a change in the weather? Surg Today 2011;41:1380-4.

19. Comelli I, Bologna A, Ticinesi A, et al. Incidence of primary spontaneous pneumothorax is not associated with microclimatic variations: results of a sevenyear survey in a temperate climate area. Monaldi Arch Chest Dis

Cite this article as: Kaneko Y, Utsushikawa Y, Deguchi H, Tomoyasu M, Kudo S, Shigeeda W, Yoshimura R, Kanno H, Saito H. Correlation with spontaneous pneumothorax and weather change, especially warm front approaching. J Thorac Dis 2021;13(3):1584-1591. doi: 10.21037/jtd-20-3395
2017;87:793.

20. Celik B, Kefeli Celik H, Hamzaçebi H, et al. The role of meteorological conditions on the development of spontaneous pneumothorax. Thorac Cardiovasc Surg 2009;57:409-12.

21. Heyndrickx M, Le Rochais JP, Icard P, et al. Do atmospheric conditions influence the first episode of primary spontaneous pneumothorax? Interact Cardiovasc Thorac Surg 2015;21:296-300.

22. Available online: https://www.data.jma.go.jp/obd/stats/ etrn/index.php. Accessed June 14,2011.

23. Yoshino M, Asano T, Kawamura T, et al. Climatology and meteorology dictionary 1985;60:400-5.

24. Park JH, Lee SH, Yun SJ, et al. Air pollutants and atmospheric pressure increased risk of ED visit for spontaneous pneumothorax. Am J Emerg Med 2018;36:2249-53. 